\title{
Overview of Gene Therapy in Spinal Muscular Atrophy and Duchenne Muscular Dystrophy
}

\author{
Nicolas Abreu ${ }^{1}$ and Megan Waldrop ${ }^{1}$ \\ ${ }^{1}$ Nationwide Children's Hospital
}

July 1,2020

\begin{abstract}
Both 5q-linked spinal muscular atrophy (SMA) and Duchenne muscular dystrophy (DMD) are fatal monogenic neuromuscular disorders caused by loss-of-function mutations. SMA is an autosomal recessive disorder affecting motor neurons that is typically caused by homozygous whole-gene deletions of SMN1. DMD is an X-linked recessive muscle disease most often due to exon deletions, but also duplications and smaller sized variants within the DMD gene. Gene replacement therapy offers the opportunity to correct the underlying genetic defect by the introduction of a functional gene. We review the transformative work from clinical trials to United States Food and Drug Administration approval of onasemnogene abeparvovec-xioi in SMA and its application in clinical practice and the early results of microdystrophin delivery in DMD. We also review the introduction of antisense oligonucleotides to alter pre-mRNA splicing to promote exon inclusion (as in nusinersen in SMA) or exclusion (as in eteplirsen in DMD) into neuromuscular therapeutics. There are multiple promising novel genetically mediated therapies on the horizon, which in aggregate point towards a hopeful future for individuals with SMA and DMD.
\end{abstract}

Abstract

Both 5q-linked spinal muscular atrophy (SMA) and Duchenne muscular dystrophy (DMD) are fatal monogenic neuromuscular disorders caused by loss-of-function mutations. SMA is an autosomal recessive disorder affecting motor neurons that is typically caused by homozygous whole-gene deletions of SMN1 . DMD is an $\mathrm{X}$-linked recessive muscle disease most often due to exon deletions, but also duplications and smaller sized variants within the $D M D$ gene. Gene replacement therapy offers the opportunity to correct the underlying genetic defect by the introduction of a functional gene. We review the transformative work from clinical trials to United States Food and Drug Administration approval of onasemnogene abeparvovec-xioi in SMA and its application in clinical practice and the early results of microdystrophin delivery in DMD. We also review the introduction of antisense oligonucleotides to alter pre-mRNA splicing to promote exon inclusion (as in nusinersen in SMA) or exclusion (as in eteplirsen in DMD) into neuromuscular therapeutics. There are multiple promising novel genetically mediated therapies on the horizon, which in aggregate point towards a hopeful future for individuals with SMA and DMD.

Manuscript

Introduction

Gene therapy provides a new avenue to treat life-limiting neuromuscular disorders. For single-gene conditions resulting from absent or reduced gene expression, as in spinal muscular atrophy (SMA) and Duchenne muscular dystrophy (DMD), the goal of gene replacement therapy is to deliver an intact copy of the disrupted gene, known as a transgene, to cells so they can express a functional protein to alleviate disease. This has been performed ex vivo for hematological and immunological disorders by removing hematopoietic stem and progenitor cells from affected individuals and introducing a transgene into the extracted cells typically using a viral vector in a tissue culture. ${ }^{1}$ The goal is to integrate the transgene into the host genome so that when 
the treated cells are reintroduced into the patient, they transfer the transgene onto their daughter cells after engraftment. In contrast, gene therapy for neuromuscular conditions requires transduction of long-lived, nonreplicating nerve and slower replicating muscle cells, and so in vivo gene therapy strategies are preferred. Here, a transgene is packaged within a viral vector and delivered directly into an affected individual, where the viral machinery allows the transgene to enter cells and replicate without need to integrate into the host genome. ${ }^{1}$

There are several considerations for in vivo gene replacement therapy in neuromuscular disease. One advantage of this method is the lack of integration of the transgene, which has been shown in some cases to result in unwanted mutations and an increased risk of cancer. ${ }^{2} \mathrm{~A}$ major advance has been the development of adeno-associated virus (AAV) vectors, which are not known to be associated with human disease and only weakly activate the innate immune system. ${ }^{3,4}$ There are many AAV serotypes that differ in terms of tissue tropism and prevalence of pre-existing antibodies in the general population, leading AAV9 to be a common vector in neuromuscular gene therapy due to its ability to efficiently transduce the nervous system and muscle, and lower prevalence of high titers of pre-existing neutralizing AAV9 antibodies in the community. ${ }^{5,6} \mathrm{~A}$ limitation to the use of an AAV vector though is its small carrying capacity of 5 kilobases, which is much smaller than the $D M D$ gene. ${ }^{7}$

Another step towards progress in neuromuscular therapeutics was the introduction of antisense oligonucleotides (ASO). Distinct from gene therapy, there is no introduction of foreign genetic material to generate novel transgene expression, but instead this is an RNA-based therapeutic strategy to alter expression of existing genes. ASOs are short sequences of modified synthetic nucleotides that bind to specific sites within pre-mRNA to alter splicing based on their design, and thereby change exon number in the mature transcript to produce a more functional protein. They may also be engineered to promote degradation of the transcript in diseases that result from toxic gain-of-function mutations, as in Huntington disease, but are not applicable in disease with loss of protein function like SMA and DMD. ${ }^{8}$

In this review, we highlight the tremendous progress in genetically mediated therapies for SMA and DMD, with a focus on ASOs and gene replacement therapy. We explore some exciting novel therapeutics using alternative strategies as well in order to show the bright future ahead for neuromuscular medicine.

1. Gene Therapy in Spinal Muscular Atrophy

2. Understanding Spinal Muscular Atrophy

Spinal muscular atrophy (SMA) results from degeneration of the anterior horn cells of the spinal cord and motor nuclei in the lower brainstem, and is associated with progressive, symmetric, proximal more than distal muscle weakness and atrophy. The most common form is due to biallelic loss-of-function variants in SMN1 (survival motor neuron 1 gene). Occurring in about 8 in 100,000 live births, it has been the leading inherited cause of infant death. ${ }^{9}$ SMN1 is located on the long arm of chromosome 5, specifically the 5 q13.2 region, and thus SMN1- related SMA may also be referred to as 5q SMA. About $94 \%$ of individuals with SMN1- related SMA carry homozygous deletions of exon 7, though alleles with smaller deletions, nonsense variants, frameshift variants, splice site mutations, and missense variants have all been described. ${ }^{10}$ There is a group of disorders known as non-5q spinal muscular atrophies that may mimic the clinical appearance to SMN1- related disease, but are due to many other genetic etiologies and often on close evaluation have distinguishing features from typical SMA. ${ }^{11}$ Hereafter, the use of SMA will exclusively refer to 5q spinal muscular atrophy.

Individual phenotypes of SMA are largely driven by copy number of a modifying gene, SMN2 . This gene is nearly identical to $S M N 1$, with a unique $\mathrm{C}$ to $\mathrm{T}$ transition in exon 7 that results in exclusion of exon 7 during post-transcriptional processing, leading to the production of mostly nonfunctional SMN protein. However, $10-15 \%$ of mRNAs from SMN2 retain exon 7 and produce some full-length SMN protein. ${ }^{12,13}$ The phenotypic severity is inversely related to the number of copies of SMN2 present, where infantile-onset SMA is typically associated with 2 copies of $S M N 2$, while adult-onset SMA is typically associated with 4 or more copies of SMN2. ${ }^{10,14,15}$ 
Prior to the onset of disease-modifying therapies, SMA was categorized into types based upon age and severity of presentation. Children with Type 0 SMA typically have 1 copy of SMN2 and have neonatal onset of symptoms, historically dying well within the first 6 months of life from respiratory complications. Type 1 SMA is the most common of the subtypes and has been classified as disease onset after birth but prior to 6 months of age, with inability to sit unassisted. ${ }^{16}$ Children with Type 1 SMA have 2-3 copies of SMN2 and have a life expectancy of about 2 years of age due to respiratory failure prior to directed treatments. ${ }^{17,18}$ Type 2 SMA is a more attenuated form, with symptom onset in later infancy or toddlerhood, being able to sit but not able to walk. They often have 3 copies of SMN2, and eventually lose the ability to sit unsupported, but two-thirds live through their mid-twenties. ${ }^{19}$ Type 3 refers to individuals who achieve the ability to walk but then lose that skill, with 3-4 copies of SMN2, and associated with a normal lifespan. For Type 4 SMA, with 4 or more copies of SMN2, symptoms begin after 30 years of age, and individuals typically continue to ambulate and have a normal life expectancy. ${ }^{19}$

Landscape of non-gene replacement therapy treatment options for Spinal Muscular Atrophy

Prior to 2016, there were no approved disease-modifying therapies in the United States for SMA. Historically, the mainstay of care focused on management of complications of the disease and improving quality of life. Supporting respiratory function, nutritional and gastrointestinal status, bone health, mobility, neurodevelopment, and psychosocial wellness were and remain cornerstones of comprehensive spinal muscular atrophy care. $^{20,21}$

The first medication approved by the U.S. Food and Drug Administration (FDA) for the treatment of SMA was nusinersen, a 2-methoxyethyl modified ASO designed to target the intronic splicing silencer N1 to suppress the routine splicing out of exon 7 from SMN2 pre-mRNA (Table 1). By displacing the hnRNP proteins at the site, nusinersen increases the synthesis of transcripts containing exon 7 and ultimately fulllength SMN protein. ${ }^{22}$ In a multicenter phase 3 randomized, double-blind, sham-controlled trial of nusinersen in infants with Type 1 SMA treated at a mean age of 7.9 weeks, the trial terminated early due to a high percentage $(41 \%)$ of treated infants showing improvement in motor milestones on Section 2 of the Hammersmith Infant Neurological Examination, compared to $0 \%$ in the control group. In the final analysis, $51 \%$ of treated infants showed a motor milestone response and an overall increased likelihood of survival over 13 months. ${ }^{23}$ This work was followed by a phase 3 trial of Type 2 SMA children aged 2-9 years. After 15 months of treatment, there was an increase in $\sim 4$ points on the Hammersmith Functional Motor ScaleExpanded compared to a decrease in $\sim 1$ point in the control group, resulting in early termination. Though, there was no significant difference between groups in the proportion of children who were able to stand alone or walk with assistance. ${ }^{24}$

For adults with Type 3 SMA treated between 18 and 59 years of age with nusinersen, they were able to walk further by a modest amount over 10 months of treatment when compared to baseline on the 6-minute walk test (mean 369.5 meters v. 377.75 at final visit) ${ }^{25}$ Nusinersen was approved by the FDA for all types of SMA and is administered intrathecally as the ASO cannot cross the blood-brain barrier. It is a life-long treatment, requiring three lumbar punctures per year in the maintenance phase after completion of four loading doses. Monitoring for thrombocytopenia, coagulation abnormalities and renal toxicity is recommended at baseline and prior to each dose. It is overall a safe and well tolerated treatment, though sedation may be necessary in young children or those with procedural anxiety, and advanced surgical planning may be needed in those considering spinal fusion for scoliosis. ${ }^{26}$

An emerging alternative to nusinersen is the orally bioavailable small molecule, risdiplam. It is in a different class of therapeutics to ASOs as risdiplam may be given enterally in liquid form daily instead of requiring intrathecal administration. ${ }^{27}$ Risdiplam is a centrally and peripherally distributed splicing modifier that binds to exon 7 of SMN2 pre-mRNA, displacing hnRNP proteins and promoting inclusion of exon 7 for production of full-length SMN protein. ${ }^{27,28}$ Risdiplam has shown to be safe in healthy volunteers despite concerns of off-target effects based on a related splicing modifier RG7800 demonstrating retinal toxicity in cynomolgus monkeys. ${ }^{29}$ Based on interim analyses of FIREFISH (NCT02913482), 93\% of SMA Type 1 infants aged 1-7 months had at least a 4 point improvement in motor functioning from baseline on the total 
score of the Children's Hospital of Philadelphia Infant Test of Neuromuscular Disorders (CHOP-INTEND) after 16 months of treatment. ${ }^{30}$ In addition, improvement in motor functioning has been suggested for treated individuals with Type 2 and Type 3 SMA ranging in age from 2 to 25 years old in a multicenter, double-blind, placebo-controlled study (SUNFISH, NCT02908685). ${ }^{31}$ As of June 2020, risdiplam remains under priority review with the FDA.

\section{Gene Replacement Therapy for children with Spinal Muscular Atrophy}

In May 2019, onasemnogene abeparvovec-xioi became the first in vivo systemically delivered gene therapy approved by the FDA (Table 1). The treatment involves a one-time intravenous (IV) administration of $S M N$ complementary DNA, from which full-length SMN protein may be produced. The transgene is under the control of a cytomegalovirus enhancer/chicken-beta-actin hybrid promoter within a self-complementary adeno-associated viral serotype 9 (scAAV9) to drive high levels of gene expression. ${ }^{32}$ This serotype of AAV is ideal due to its ability to cross the blood-brain barrier and its robust transduction of brain and spinal cord neurons, including alpha motor neurons known to underlie the pathogenesis of SMA. ${ }^{33}$ The engineering of a self-complementary template allows the coding region of the recombinant virus to form an intramolecular double-stranded DNA, allowing for efficient replication and transcription rather than waiting for host cell-mediated synthesis of the second strand. ${ }^{34}$ One-time administration is possible based upon the longevity and non-replicating nature of motor neurons.

In an SMA mouse model with a typical lifespan of 13 days, gene replacement using 5x10e11 genomes demonstrated excellent motor outcomes and survival was extended from a median age of 15.5 days in a group treated with scAAV9 without SMN to more than 250 days in the treated cohort with scAAV9-SMN when administered intravascularly on postnatal day $1 .^{32,35}$ There was partial improvement in survival when mice were treated at postnatal day 5 , and little effect at postnatal day 10, which may be related to physiologic postnatal astrocyte genesis and associated trapping of AAV9 in mice. ${ }^{36}$

In the landmark phase 1/2a, open-label, dose escalation trial of onasemnogene abeparvovec of 15 Type 1 SMA children with two copies of SMN2 treated between 0.9 and 7.9 months of age, there was marked improvement in motor milestones and all had event-free survival (ventilatory support $<16$ hours per day) compared to $8 \%$ of natural history controls at 20 months of age. Of the 12 individuals in the high-dose cohort (2x10e14 vector genomes/kilogram of body weight), 11 were able to sit unassisted for at least 5 seconds, 9 for at least 30 seconds, 9 could roll over, and 2 were able to crawl and walk independently. ${ }^{37}$

After the first patient was noted to have significantly elevated serum aminotransferase levels, alanine aminotransferase (ALT) 31X ULN and aspartate aminotransferase (AST) 14X ULN but without clinical manifestations, subsequent patients were immunosuppressed with prednisolone $1 \mathrm{mg} / \mathrm{kg}$ for 30 days starting 1 day prior to gene transfer. Prednisolone attenuated this response, with only three individuals in the high-dose cohort showing elevations in AST and ALT. Two had elevations of less than 10X ULN, and one individual had elevations that required additional prednisolone as a result of ALT at 35X ULN and AST at 37X ULN. ${ }^{37}$ All aminotransferase elevations were transient and asymptomatic.

Follow-up for an additional two years post-gene transfer revealed two additional patients achieved independent sitting for at least 30 seconds and two others achieved standing with support. ${ }^{38}$ In addition, the majority $(11 / 12)$ of children tolerated at least partial oral feeding safely and spoke by the end of long-term follow-up. Dosing earlier than three months of age may be associated with greater improvement in motor outcomes, and to this point, the oldest patient in the trial at 7.9 months (also with low baseline motor functioning) demonstrated only modest improvement in functioning. ${ }^{38}$

Phase 3 trials are underway in the United States, Europe, and East Asia, as well as trials exploring presymptomatic treatment and intrathecal onasemnogene abeparvovec-xioi administration for individuals with moreSMN2 copies (NCT03505099, NCT03306277, NCT03461289, NCT03837184, NCT03381729), with encouraging interim results. ${ }^{39}$ As of June 2020, the open-label phase 1/2a trial of intrathecal onasemnogene abeparvovec remains on a partial hold by the FDA after review of non-human primate data demonstrating inflammation of the dorsal root ganglia, which has not been seen in any humans who had already received 
intrathecal gene transfer. ${ }^{40}$

The clinical practice of gene therapy for Spinal Muscular Atrophy

Newborn screening for SMA has revolutionized care, allowing early identification of SMA and thus maximizing response to gene transfer. ${ }^{41-43}$ While SMA was included in the recommended U.S. universal screening program for newborn screening in 2018, implementation is slow and is currently active in only a minority of states. ${ }^{44}$ While initial clinical trials of gene replacement therapy targeting young infants with SMA with 2 copies of SMN2 , FDA approval for onasemnogene abeparvovec-xioi was granted for all children with SMA less than 2 years of age without end-stage disease. ${ }^{5}$

Once an eligible individual is identified via newborn screen or in clinic, confirmatory SMA genetic testing with SMN2 copy number should be completed (Figure 1). Once the genetic diagnosis is confirmed, a safety evaluation with AAV9 titers and baseline "SMA gene transfer laboratories" (ALT, AST, bilirubin, prothrombin time, platelet counts, as well as consideration of human immunodeficiency virus (HIV), hepatitis $\mathrm{B}$ and $\mathrm{C}$ serologies) are essential prior to onasemnogene abeparvovec administration. ${ }^{45}$ Elevated AAV9 titers may increase risk of immunogenicity and limit efficacy of treatment, and so individuals with anti-AAV9 antibody titers greater than 1:50 have been excluded from intervention. ${ }^{45}$ The prescribing information also recommends monitoring troponin I levels at baseline and after treatment to monitor for cardiac effects, although no clinical cardiac toxicity has been noted. ${ }^{37}$

Onasemnogene abeparvovec is given via IV infusion over 60 minutes at a dose of $1.1 \mathrm{x} 10 \mathrm{e} 14 \mathrm{vg} / \mathrm{kg}{ }^{37,45}$ Prednisolone $1 \mathrm{mg} / \mathrm{kg}$ /day begins one day prior to gene transfer, and is recommended for at least 30 days prior to weaning, with adjustment in dosing depending on ongoing monitoring; in some instances, the prednisolone dose may need to be increased to further suppress the AAV9 immune response. ${ }^{37}$ Weekly laboratory monitoring should continue until AST and ALT are normalizing $(<2 \mathrm{X}$ ULN) and then may be spaced out. The most common side effects include vomiting and elevated aminotransferases. Onasemnogene abeparvovec-xioi carries a black box warning of acute liver injury after an individual with Type 1 SMA with premorbid elevated aminotransferases developed acute liver injury with jaundice, AST 80X ULN and ALT 45X ULN, and massive inflammation of liver biopsy 7 weeks after treatment administration under the managed access program. ${ }^{45}$ The child returned to baseline status after use of corticosteroids and had already completed the recommended 30 days of $1 \mathrm{mg} / \mathrm{kg}$ of prednisolone and a 2-week taper. There is also description of transient decreases in platelet counts and elevations in cardiac troponin-I levels of unclear clinical significance. ${ }^{45}$ Overall, onasemnogene abeparvovec is a safe and highly effective treatment when care is given to treat children with no underlying liver dysfunction, and prednisolone is adjusted based upon close monitoring throughout the immediate post-treatment period.

Although the viral vector for onasemnogene abeparvovec-xioi does not cause human disease, guardians and childcare providers of infants who undergo gene transfer are counseled on use of protective gloves when coming into direct contact with patient bodily fluids and waste, as well as good hand hygiene for 4-6 weeks after administration to minimize exposures as a result of viral shedding. If exposed, caregivers may develop AAV9 immunity precluding them from future potential AAV9 therapies. Breastfeeding was restricted in the phase 1 trial before, during, and 30 days after gene transfer out of the theoretical risk of passive maternal transfer of anti-AAV9 antibodies, however the risks and benefits should be weighed on an individual basis with the treating physician. ${ }^{5,37,45}$ Vaccinations may be adjusted at the discretion of the treating physician and may be given at least one week prior to gene transfer. Inactivated vaccinations may be given at any time post gene transfer, but live attenuated vaccines should not be given until 4 weeks after completing the prednisolone course..$^{5,37,46,47}$

1. Gene Therapy in Duchenne Muscular Dystrophy

2. Understanding Duchenne Muscular Dystrophy

Duchenne muscular dystrophy (DMD) is on the severe end of the spectrum of X-linked dystrophinopathies, which are life-limiting muscle diseases associated with mutations in the dystrophin-encoding gene, $D M D$. DMD is characterized by loss of ambulation prior to age 13 while the milder form, Becker muscular dystrophy, 
has a wide phenotypic spectrum with loss of ambulation after 16 years or not at all. Dystrophin is located on the cytoplasmic side of the muscle fiber plasma membrane, providing structural integrity to the cell when bound to the associated transmembrane glycoprotein complex. Absence of dystrophin causes muscle membrane instability, leading to degeneration with impaired regeneration, fibrosis and fatty infiltration in muscle. $^{48}$

DMD is identified in about 1 in 5000 to 6000 live male births. ${ }^{49,50}$ Although males are mostly affected as this is an X-linked recessive disorder, symptomatic female carriers have been described with variable age of onset and severity of symptoms. ${ }^{51}$ Early symptoms of DMD include delayed gross motor milestones, calf enlargement, a waddling gait, toe-walking, and a Gower's maneuver. Symptoms are first noticed 2-3 years of age, though significant delays in diagnosis occur. ${ }^{52}$ Diagnosis is confirmed with $D M D$ deletion and duplication analysis and sequencing, though in very rare instances muscle mRNA analysis may be needed. ${ }^{53}$

Approximately $60-70 \%$ of dystrophinopathies result from deletions of one or more exons within the $D M D$ gene. ${ }^{54,55}$ Less common mutations include intragenic duplications, single nucleotide variants, splice site changes, and deletions and insertions of a few nucleotides. Clinicians typically use the reading frame rule to assist in phenotype predictions. Deletions that result in a shift in the mRNA translational reading frame (out-of-frame deletions) lead to very minimal or absent dystrophin production and a more severe DMD phenotype. Deletions that preserve the translational reading frame (in-frame deletions) lead to incomplete dystrophin production with some residual function and are predicted to lead to a milder BMD phenotype. About $90 \%$ of individuals with DMD due to intragenic deletions are out-of-frame, though this is not as consistently seen in BMD with in-frame deletions. ${ }^{56-58}$

DMD results in multisystem dysfunction as a result of the underlying muscle disease, as well as adverse effects from long-term enteral corticosteroids used as a part of current standard of care. DMD-associated cardiomyopathy and conduction defects will be explored in more detail in other articles in this special edition, as well as the respiratory complications from progressive loss of strength of respiratory and bulbar muscles. Gastrointestinal function is also affected, with constipation, reflux and delayed gastric emptying that in part may be related to altered function of dystrophin in smooth muscle in the gastrointestinal tract. Short stature, obesity and low bone mineral density are common and may be complicated by corticosteroid use. Orthopedic sequelae include contractures and scoliosis. Neurodevelopmental disorders like intellectual disability, learning disabilities, autism spectrum disorder and attention-deficit hyperactivity disorder, are seen at higher rates compared to the general population. ${ }^{59,60}$ Further, patients and their caregivers are at increased risk of depression and anxiety. Multidisciplinary muscular dystrophy care is vital to address the many needs of these individuals and ensure the best possible outcomes. ${ }^{61-63}$ Although advances like scoliosis surgery and non-invasive ventilation have increased the median survival of individuals with DMD to 30 years, the importance of disease-directed therapies remains. ${ }^{64}$

\section{Landscape of non-gene therapy treatment options for Duchenne Muscular Dystrophy}

Glucocorticoids have been the long-standing crux of neuromuscular care for DMD, first showing benefit in $1974 .{ }^{65}$ Their specific mechanism of action in DMD and effects in BMD remain unknown. Prednisone and deflazacort, a corticosteroid prodrug, improve motor functioning, delay onset of cardiomyopathy, reduce the need for scoliosis surgery, and may prolong survival (Table 1). ${ }^{66,67}$ Daily corticosteroid use is not without side effects and alternative dosing regimens have been suggested, including weekend dosing, which may be equally beneficial for motor outcomes and have less effects on weight gain or reduction in linear growth. ${ }^{68}$ Treatment has evolved from initiation at the start of motor decline, to more recently around 4-5 years of age prior to decline in motor skills, though there may be benefit to starting at an even younger age with a weekend dosing regimen. ${ }^{69}$ Medication typically continues indefinitely while monitoring for side effects, which may prompt dose reductions. Weight gain, hirsutism and cushingoid appearance are the most common side effects, though short stature, delayed puberty, fractures, reflux, hypertension, cataracts, acne, striae, and behavioral dysregulation all may occur. Physicians, patients and families must also be aware of the possible need for stress-dose steroids around the time of illness or scheduled surgeries in order to prevent adrenal crises. 
Despite decades of research on the genetics and spectrum of mutations of DMD, novel treatments addressing the underlying pathophysiology have only recently emerged. Exon skipping interventions were the first viable precision therapies for DMD. Exon skipping relies on the use of antisense oligonucleotides (ASO) to bind at a specific location of the DMD pre-mRNA, altering splicing to exclude the exon in the mature mRNA. ${ }^{8}$ When applied in DMD to deletions that disrupt the reading frame, masking one exon may restore the reading frame and result in some expression of shortened but functional dystrophin.

Eteplirsen is a first-generation morpholino ASO, otherwise known as a phosphorodiamidate morpholino oligomer (PMO), that has modifications to the ribose sugar to avoid degradation from nucleases and improve target affinity. It promotes exon 51 exclusion and restores the reading frame in individuals with amenable mutations (e.g., deletions of exons $48-50$ or exon 52). Despite the large number of variants, $\sim 13 \%$ of all individuals with DMD bear exon 51 skipping-amenable mutations. The second and third most applicable sites for single exon skipping are at exon 45 and 53, making up $8.1 \%$ and $7.7 \%$ of all DMD mutations respectively. ${ }^{70}$ Eteplirsen is administered by IV infusion weekly, typically via an implanted central venous catheter. Clinical trials of the PMO have demonstrated a small but significant amount of dystrophin expression, attenuation of respiratory decline based on forced vital capacity, and improved ambulation in the majority of treated individuals when compared to historical controls. ${ }^{71-75}$ The FDA approved eteplirsen in September 2016 based on limited data using the surrogate marker of dystrophin expression, no adverse events and the expectation of future clinical benefit (Table 1$).^{76}$

The second ASO to be approved by the FDA for DMD was the exon 53-skipping PMO, golodirsen (Table 1). With once weekly IV infusions over 48 weeks, 25 individuals with DMD showed increased dystrophin expression compared to baseline. ${ }^{77}$ The FDA noted concerns of renal toxicity seen in animal models treated with a 10X higher dose than what has been used in humans, as well as risk of indwelling catheter infections in their initial rejection, requesting renal function monitoring and demonstration of meaningful change in functional outcomes in the larger scale phase 3 ESSENCE trial (NCT02500381) that is currently underway. ${ }^{78}$

Ataluren is a distinct small molecule therapy administered enterally that induces ribosomal readthrough of premature stop codons as a result of DMD nonsense mutations, which comprise about $10 \%$ of all DMD cases (Table 1)..$^{54,79}$ While the primary endpoint of improvement in ambulation was not met in the phase 3 trial, additional analyses and review of registry data suggest a benefit. ${ }^{80-82}$ Ataluren has conditional authorization in Europe by the EMA, but is not approved by the FDA. ${ }^{83,84}$ There are a number of other small molecule therapies, exon-skipping technologies, and steroidal therapies currently under investigation or under FDA review that are beyond the scope of this review. ${ }^{85-87}$

Gene transfer for children with Duchenne Muscular Dystrophy

Gene replacement therapy in DMD holds great promise among emerging therapies by directly providing a functional copy of the $D M D$ gene, addressing the underlying genetic defect regardless of the underlying mutation. With the discovery of AAV vectors, efficient transgene transduction in muscle was achieved without the challenges seen with in vivo use of adenovirus or lentivirus vectors. ${ }^{3}$ However, due to the large size of the dystrophin gene and small carrying capacity of AAV vectors, researchers have designed synthetic microdystrophins, removing many of the spectrin-like repeats and the C-terminal domain to produce a transgene that may fit within an $\mathrm{AAV}$ vector and produce a functional, internally truncated protein akin to "in-frame" BMD-like mutations. ${ }^{3}$ The first in-human trial of AAV-mediated gene transfer in DMD was performed in 6 patients via intramuscular delivery. Safety was established, but transfer resulted in no significant levels of microdystrophin expression. ${ }^{88}$ In addition, evidence of immunogenicity was noted with detectable T-cell responses to the AAV vector and the microdystrophin transgene. This informed subsequent trials by highlighting challenges with pre-existing neutralizing antibodies against the vector, poor vector uptake due to AAV2.5 serotype, and lack of tissue specificity of the CMV early enhancer plus promoter, which may have boosted the immune response. ${ }^{3,88,89}$ There are three active IV microdystrophin trials in the United States with important differences in AAV serotype, promoter, transgene, and inclusion criteria (NCT03769116,, NCT03362502, NCT03368742). ${ }^{3}$ 
Results from an open-label phase 1/2a trial of systemic microdystrophin in four children with DMD using an AAVrh74 vector and MHCK7 promoter revealed high levels of microdystrophin expression 12 weeks after gene transfer and functional improvements in motor outcome measures sustained over a 1-year period. ${ }^{90}$ All participants showed a reduction in creatine kinase levels at 1 year of age (though levels fluctuated in between), and all scores improved by at least 2 points on the North Star Ambulatory Assessment compared to baseline. The treatment was safe, with self-limited vomiting and transient liver enzyme elevations as the most common adverse effects. A dose of $2.0 \times 10 \mathrm{e} 14 \mathrm{vg} / \mathrm{kg}$ was used in boys aged 4-6 years and AAVrh74binding antibodies were permitted up to 1:400. ${ }^{37,90}$ All children were on a weekend steroid regimen prior to enrollment, and so an additional $1 \mathrm{mg} / \mathrm{kg}$ daily dose of prednisone (or equivalent) was given each weekday for 30 days and weaned over $2-4$ weeks. In this small sample, there were only modest elevations of liver enzymes, with gamma-glutamyltransferase peaking at four times ULN. It is not clear if this milder hepatic response than as was seen with onasemnogene abeparvovec in SMA may be due to sample size, engineering or specifics of the vector or transgene, or pre-existing use of steroids as standard-of-care in DMD. A doubleblind, placebo-controlled trial is underway (NCT03769116).

Surrogate gene therapy represents another mutation-independent therapeutic avenue by delivery of genes via $A A V$ vectors that can substitute for dystrophin. Utrophin bears much of the structural and functional elements of dystrophin, and its upregulation via AAV-mediated gene transfer has been successful at restoring muscle function in animal models. ${ }^{91}$ Similarly, B4GALNT2 (GALGT2) upregulation via AAV-mediated delivery results in increased expression of dystrophin-associated proteins, correction of muscle histopathology, and improvement in cardiac function in preclinical studies. ${ }^{92-94}$ Their clinical benefit in children with DMD remains unknown.

\section{Conclusions}

Precision medicine for neuromuscular disorders has transformed in the past decade with commercially available gene replacement therapy for SMA and ASOs for both SMA and DMD. Additional small molecule and gene therapies are currently in development for these and other neuromuscular conditions, like risdiplam for SMA and gene replacement therapy for DMD and X-linked myotubular myopathy. ${ }^{27,86,95-97}$ Further, gene editing using CRISPR/Cas9 systems has been successful in large animal models in DMD and are progressing in their development toward human applications. ${ }^{98}$ Yet, as exciting as these treatments are, clinicians must remain committed to continued multidisciplinary care of the complications of the underlying neuromuscular disease as we are learning about the long-term safety and longevity of these therapies. Efforts to expand gene therapy for SMA for those of older ages (NCT03381729) are ongoing, along with research on how to safely and effectively treat those with pre-existing AAV antibodies. ${ }^{99,100}$ It is unknown if the combination of gene replacement with other genetically-mediated therapies will provide added benefit. This requires further evaluation as families and health care systems are facing the high costs of these interventions. ${ }^{101,102}$ By fostering collaboration between researchers, clinicians, patient advocacy groups, government, and industry, the field will continue to move forward in this new era of neuromuscular medicine.

\section{References}

1. High KA, Roncarolo MG. Gene therapy. New England Journal of Medicine. 2019;381(5):455-464. doi:10.1056/NEJMra1706910

2. Howe SJ, Mansour MR, Schwarzwaelder K, Bartholomae C, Hubank M, Kempski H, Brugman MH, Pike-Overzet K, Chatters SJ, De Ridder D, et al. Insertional mutagenesis combined with acquired somatic mutations causes leukemogenesis following gene therapy of SCID-X1 patients. Journal of Clinical Investigation. 2008;118(9):3143-3150. doi:10.1172/JCI35798

3. Duan D. Systemic AAV Micro-dystrophin Gene Therapy for Duchenne Muscular Dystrophy. Molecular Therapy. 2018;26(10):2337-2356. https://doi.org/10.1016/j.ymthe.2018.07.011. doi:10.1016/j.ymthe.2018.07.011

4. Shirley JL, de Jong YP, Terhorst C, Herzog RW. Immune Responses to Viral Gene Ther- 
apy Vectors. Molecular Therapy. 2020;28(3):709-722. https://doi.org/10.1016/j.ymthe.2020.01.001. doi:10.1016/j.ymthe.2020.01.001

5. Al-Zaidy SA, Mendell JR. From Clinical Trials to Clinical Practice: Practical Considerations for Gene Replacement Therapy in SMA Type 1. Pediatric Neurology. 2019;100:3-11. https://doi.org/10.1016/j.pediatrneurol.2019.06.007. doi:10.1016/j.pediatrneurol.2019.06.007

6. Boutin S, Monteilhet V, Veron P, Leborgne C, Benveniste O, Montus MF, Masurier C. Prevalence of serum IgG and neutralizing factors against adeno-associated virus (AAV) types 1, 2, 5, 6, 8, and 9 in the healthy population: Implications for gene therapy using AAV vectors. Human Gene Therapy. 2010;21(6):704-712. doi:10.1089/hum.2009.182

7. Dong JY, Fan PD, Frizzell RA. Quantitative analysis of the packaging capacity of recombinant adenoassociated virus. Human Gene Therapy. 1996;7(17):2101-2112. doi:10.1089/hum.1996.7.17-2101

8. Scoles DR, Minikel E V, Pulst SM. Antisense oligonucleotides A primer. Neurol Genet. 2019;5:323. doi:10.1212/NXG.0000000000000323

9. Mostacciuolo ML, Danieli GA, Trevisan C, Müller E, Angelini C. Epidemiology of spinal muscular atrophies in a sample of the Italian population. Neuroepidemiology. 1992 [accessed 2020 May 10];11(1):3438. https://www.karger.com/Article/FullText/110905. doi:10.1159/000110905

10. Wirth B. An update of the mutation spectrum of the survival motor neuron gene (SMN1) in autosomal recessive spinal muscular atrophy (SMA). Human Mutation. 2000;15(3):228-237. doi:10.1002/(SICI)10981004(200003)15:3<228::AID-HUMU3>3.0.CO;2-9

11. Darras BT. Non-5q spinal muscular atrophies: The alphanumeric soup thickens. Neurology. 2011 [accessed 2020 May 10];77(4):312-314. http://www.ncbi.nlm.nih.gov/sites/. doi:10.1212/WNL.0b013e3182267bd8

12. Lorson CL, Hahnen E, Androphy EJ, Wirth B. A single nucleotide in the SMN gene regulates splicing and is responsible for spinal muscular atrophy. Proceedings of the National Academy of Sciences of the United States of America. 1999;96(11):6307-6311. doi:10.1073/pnas.96.11.6307

13. Butchbach MER. Copy number variations in the survival motor neuron genes: Implications for spinal muscular atrophy and other neurodegenerative diseases. Frontiers in Molecular Biosciences. 2016;3(MAR):110. doi:10.3389/fmolb.2016.00007

14. Calucho M, Bernal S, Alías L, March F, Venceslá A, Rodríguez-Álvarez FJ, Aller E, Fernández RM, Borrego S, Millán JM, et al. Correlation between SMA type and SMN2 copy number revisited: An analysis of 625 unrelated Spanish patients and a compilation of 2834 reported cases. Neuromuscular Disorders. 2018 [accessed 2020 Jun 2];28(3):208-215. https://doi.org/10.1016/j.nmd.2018.01.003. doi:10.1016/j.nmd.2018.01.003

15. Wirth B, Brichta L, Schrank B, Lochmüller H, Blick S, Baasner A, Heller R. Mildly affected patients with spinal muscular atrophy are partially protected by an increased SMN2 copy number. Human Genetics. 2006;119(4):422-428. doi:10.1007/s00439-006-0156-7

16. Russman BS. Spinal muscular atrophy: Clinical classification and disease heterogeneity. Journal of Child Neurology. 2007;22(8):946-951. doi:10.1177/0883073807305673

17. Finkel RS, McDermott MP, Kaufmann P, Darras BT, Chung WK, Sproule DM, Kang PB, Reghan Foley A, Yang ML, Martens WB, et al. Observational study of spinal muscular atrophy type I and implications for clinical trials. Neurology. 2014;83(9):810-817. doi:10.1212/WNL.0000000000000741

18. Kolb SJ, Coffey CS, Yankey JW, Krosschell K, Arnold WD, Rutkove SB, Swoboda KJ, Reyna SP, Sakonju A, Darras BT, et al. Natural history of infantile-onset spinal muscular atrophy. Annals of Neurology. 2017;82(6):883-891. doi:10.1002/ana.25101

19. Zerres K, Schöneborn SR. Natural History in Proximal Spinal Muscular Atrophy: Clinical Analysis of 445 Patients and Suggestions for a Modification of Existing Classifications. Archives of Neurology. 
1995;52(5):518-523. doi:10.1001/archneur.1995.00540290108025

20. Mercuri E, Finkel RS, Muntoni F, Wirth B, Montes J, Main M, Mazzone E, Vitale M, Snyder B, Quijano-Roy S, et al. Diagnosis and management of spinal muscular atrophy: Part 1: Recommendations for diagnosis, rehabilitation, orthopedic and nutritional care. Neuromuscular Disorders. 2018;28(2):103-115. doi:10.1016/j.nmd.2017.11.005

21. Finkel RS, Mercuri E, Meyer OH, Simonds AK, Schroth MK, Graham RJ, Kirschner J, Iannaccone ST, Crawford TO, Woods S, et al. Diagnosis and management of spinal muscular atrophy: Part 2: Pulmonary and acute care; medications, supplements and immunizations; other organ systems; and ethics. Neuromuscular Disorders. 2018;28(3):197-207. doi:10.1016/j.nmd.2017.11.004

22. Chiriboga CA, Swoboda KJ, Darras BT, Iannaccone ST, Montes J, De Vivo DC, Norris DA, Bennett CF, Bishop KM. Results from a phase 1 study of nusinersen (ISIS-SMN Rx) in children with spinal muscular atrophy. Neurology. 2016;86(10):890-897. doi:10.1212/WNL.0000000000002445

23. Finkel RS, Mercuri E, Darras BT, Connolly AM, Kuntz NL, Kirschner J, Chiriboga CA, Saito K, Servais L, Tizzano E, et al. Nusinersen versus sham control in infantile-onset spinal muscular atrophy. New England Journal of Medicine. 2017;377(18):1723-1732. doi:10.1056/NEJMoa1702752

24. Mercuri E, Darras BT, Chiriboga CA, Day JW, Campbell C, Connolly AM, Iannaccone ST, Kirschner J, Kuntz NL, Saito K, et al. Nusinersen versus sham control in later-onset spinal muscular atrophy. New England Journal of Medicine. 2018 [accessed 2020 May 12];378(7):625-635. http://www.nejm.org/doi/10.1056/NEJMoa1710504. doi:10.1056/NEJMoa1710504

25. Walter MC, Wenninger S, Thiele S, Stauber J, Hiebeler M, Greckl E, Stahl K, Pechmann A, Lochmüller H, Kirschner J, et al. Safety and treatment effects of nusinersen in longstanding adult 5q-SMA type 3 - A prospective observational study. Journal of Neuromuscular Diseases. 2019;6(4):453-465. doi:10.3233/JND190416

26. Labianca L, Weinstein SL. Scoliosis and spinal muscular atrophy in the new world of medical therapy: Providing lumbar access for intrathecal treatment in patients previously treated or undergoing spinal instrumentation and fusion. Journal of Pediatric Orthopaedics Part B. 2019;28(4):393-396. doi:10.1097/BPB.0000000000000632

27. Ratni H, Ebeling M, Baird J, Bendels S, Bylund J, Chen KS, Denk N, Feng Z, Green L, Guerard M, et al. Discovery of Risdiplam, a Selective Survival of Motor Neuron-2 (SMN2) Gene Splicing Modifier for the Treatment of Spinal Muscular Atrophy (SMA). Journal of Medicinal Chemistry. 2018;61(15):6501-6517. doi:10.1021/acs.jmedchem.8b00741

28. Sivaramakrishnan M, McCarthy KD, Campagne S, Huber S, Meier S, Augustin A, Heckel T, Meistermann H, Hug MN, Birrer P, et al. Binding to SMN2 pre-mRNA-protein complex elicits specificity for small molecule splicing modifiers. Nature Communications. 2017 [accessed 2020 May 12];8(1). www.nature.com/naturecommunications. doi:10.1038/s41467-017-01559-4

29. Sturm S, Günther A, Jaber B, Jordan P, Al Kotbi N, Parkar N, Cleary Y, Frances N, Bergauer T, Heinig K, et al. A typ 1 healthy male volunteer single escalating dose study of the pharmacokinetics and pharmacodynamics of risdiplam (RG7916, RO7034067), a SMN2 splicing modifier. British Journal of Clinical Pharmacology. 2019;85(1):181-193. doi:10.1111/bcp.13786

30. Baranello G, Servais L, Day J, Deconinck N, Mercuri E, Klein A, Darras B, Masson R, Kletzl H, Cleary Y, et al. P.353FIREFISH Part 1: 16-month safety and exploratory outcomes of risdiplam (RG7916) treatment in infants with type 1 spinal muscular atrophy. Neuromuscular Disorders. 2019 [accessed 2020 Jun 30];29:S184. http://www.nmd-journal.com/article/S0960896619309034/fulltext. doi:10.1016/j.nmd.2019.06.515

31. Mercuri E, Baranello G, Kirschner J, Servais L, Goemans N, Pera M, Tichy M, Yeung W, Kletzl H, Gerber M, et al. O.41Sunfish part 1: 18-month safety and exploratory outcomes of risdiplam (RG7916) 
treatment in patients with type 2 or 3 spinal muscular atrophy. Neuromuscular Disorders. 2019;29:S208. doi:10.1016/j.nmd.2019.06.595

32. Foust KD, Wang X, McGovern VL, Braun L, Bevan AK, Haidet AM, Le TT, Morales PR, Rich MM, Burghes AHM, et al. Rescue of the spinal muscular atrophy phenotype in a mouse model by early postnatal delivery of SMN. Nature Biotechnology. 2010;28(3):271-274. doi:10.1038/nbt.1610

33. Foust KD, Nurre E, Montgomery CL, Hernandez A, Chan CM, Kaspar BK. Intravascular AAV9 preferentially targets neonatal neurons and adult astrocytes. Nature Biotechnology. 2009;27(1):59-65. doi:10.1038/nbt.1515

34. McCarty DM, Monahan PE, Samulski RJ. Self-complementary recombinant adeno-associated virus (scAAV) vectors promote efficient transduction independently of DNA synthesis. Gene therapy. 2001 [accessed 2020 May 14];8(16):1248-54. http://www.ncbi.nlm.nih.gov/pubmed/11509958. doi:10.1038/sj.gt.3301514

35. Valori CF, Ning K, Wyles M, Mead RJ, Grierson AJ, Shaw PJ, Azzouz M. Systemic delivery of scAAV9 expressing SMN prolongs survival in a model of spinal muscular atrophy. Science Translational Medicine. 2010 [accessed 2020 May 14];2(35). www.ScienceTranslationalMedicine.org. doi:10.1126/scitranslmed.3000830

36. Saunders NR, Joakim Ek C, Dziegielewska KM. The neonatal blood-brain barrier is functionally effective, and immaturity does not explain differential targeting of AAV9. Nature Biotechnology. 2009;27(9):804. doi:10.1038/nbt0909-804

37. Mendell JR, Al-Zaidy S, Shell R, Arnold WD, Rodino-Klapac LR, Prior TW, Lowes L, Alfano L, Berry $\mathrm{K}$, Church K, et al. Single-dose gene-replacement therapy for spinal muscular atrophy. New England Journal of Medicine. 2017;377(18):1713-1722. doi:10.1056/NEJMoa1706198

38. Al-Zaidy S, Pickard AS, Kotha K, Alfano LN, Lowes L, Paul G, Church K, Lehman K, Sproule DM, Dabbous O, et al. Health outcomes in spinal muscular atrophy type 1 following AVXS-101 gene replacement therapy. Pediatric Pulmonology. 2019;54(2):179-185. doi:10.1002/ppul.24203

39. One-Time Intrathecal (IT) Administration of AVXS-101 IT Gene Therapy for Spinal Muscular Atrophy: Phase 1 Study (STRONG) | MDA Clinical \& Scientific Conference 2020. [accessed 2020 May 14]. https://mdaconference.org/node/941

40. Cause of Inflammation That Led to AVXS-101 Trial Hold "Unknown," Novartis Says. [accessed 2020 May 14]. https://smanewstoday.com/2019/11/11/cause-of-inflammation-that-led-to-avxs-101-trialhold-unknown-novartis-says/

41. Glascock J, Sampson J, Haidet-Phillips A, Connolly A, Darras B, Day J, Finkel R, Howell RR, Klinger K, Kuntz N, et al. Treatment Algorithm for Infants Diagnosed with Spinal Muscular Atrophy through Newborn Screening. Journal of neuromuscular diseases. 2018;5(2):145-158. doi:10.3233/JND-180304

42. Glascock J, Sampson J, Connolly AM, Darras BT, Day JW, Finkel R, Howell RR, Klinger KW, Kuntz N, Prior T, et al. Revised Recommendations for the Treatment of Infants Diagnosed with Spinal Muscular Atrophy Via Newborn Screening Who Have 4 Copies of SMN2. Journal of Neuromuscular Diseases. 2020;7(2):97-100. doi:10.3233/JND-190468

43. Lowes LP, Alfano LN, Arnold WD, Shell R, Prior TW, McColly M, Lehman KJ, Church K, Sproule DM, Nagendran S, et al. Impact of Age and Motor Function in a Phase 1/2A Study of Infants With SMA Type 1 Receiving Single-Dose Gene Replacement Therapy. Pediatric Neurology. 2019;98:39-45. https://doi.org/10.1016/j.pediatrneurol.2019.05.005. doi:10.1016/j.pediatrneurol.2019.05.005

44. Kellar-Guenther Y, McKasson S, Hale K, Singh S, Sontag MK, Ojodu J. Implementing Statewide Newborn Screening for New Disorders: U.S. Program Experiences. International Journal of Neonatal Screening. 2020 [accessed 2020 May 15];6(2):35. https://www.mdpi.com/2409-515X/6/2/35. doi:10.3390/ijns6020035

45. FDA. Highlights of Prescribing Information - Zolgensma. www.fda.gov/medwatch. 
46. Rubin LG, Levin MJ, Ljungman P, Davies EG, Avery R, Tomblyn M, Bousvaros A, Dhanireddy S, Sung L, Keyserling H, et al. 2013 IDSA clinical practice guideline for vaccination of the immunocompromised host. Clinical Infectious Diseases. 2014 [accessed 2020 May 16];58(3). https://academic.oup.com/cid/articleabstract/58/3/e44/336537. doi:10.1093/cid/cit684

47. Immunization and Other Considerations in Immunocompromised Children | Red Book $(\mathbb{R}$ 2018 | Red Book Online | AAP Point-of-Care-Solutions. [accessed 2020 Jun 2]. https://redbook.solutions.aap.org/chapter.aspx?sectionId=189639978\&bookId=2205\&resultClick=1

48. Petrof BJ, Shrager JB, Stedman HH, Kelly AM, Sweeney HL. Dystrophin protects the sarcolemma from stresses developed during muscle contraction. Proceedings of the National Academy of Sciences of the United States of America. 1993;90(8):3710-3714. doi:10.1073/pnas.90.8.3710

49. Mendell JR, Shilling C, Leslie ND, Flanigan KM, Al-Dahhak R, Gastier-Foster J, Kneile K, Dunn DM, Duval B, Aoyagi A, et al. Evidence-based path to newborn screening for duchenne muscular dystrophy. Annals of Neurology. 2012;71(3):304-313. doi:10.1002/ana.23528

50. Moat SJ, Bradley DM, Salmon R, Clarke A, Hartley L. Newborn bloodspot screening for Duchenne Muscular Dystrophy: 21 years experience in Wales (UK). European Journal of Human Genetics. 2013;21(10):1049-1053. doi:10.1038/ejhg.2012.301

51. Soltanzadeh P, Friez MJ, Dunn D, von Niederhausern A, Gurvich OL, Swoboda KJ, Sampson JB, Pestronk A, Connolly AM, Florence JM, et al. Clinical and genetic characterization of manifesting carriers of DMD mutations. Neuromuscular Disorders. 2010;20(8):499-504. doi:10.1016/j.nmd.2010.05.010

52. Ciafaloni E, Fox DJ, Pandya S, Westfield CP, Puzhankara S, Romitti PA, Mathews KD, Miller TM, Matthews DJ, Miller LA, et al. Delayed Diagnosis in Duchenne Muscular Dystrophy: Data from the Muscular Dystrophy Surveillance, Tracking, and Research Network (MD STARnet). Journal of Pediatrics. 2009;155(3):380385. doi:10.1016/j.jpeds.2009.02.007

53. Gurvich OL, Tuohy TM, Howard MT, Finkel RS, Medne L, Anderson CB, Weiss RB, Wilton SD, Flanigan KM. DMD pseudoexon mutations: Splicing efficiency, phenotype, and potential therapy. Annals of Neurology. 2008;63(1):81-89. doi:10.1002/ana.21290

54. Bladen CL, Salgado D, Monges S, Foncuberta ME, Kekou K, Kosma K, Dawkins H, Lamont L, Roy AJ, Chamova T, et al. The TREAT-NMD DMD global database: Analysis of more than 7,000 duchenne muscular dystrophy mutations. Human Mutation. 2015;36(4):395-402. doi:10.1002/humu.22758

55. Takeshima Y, Yagi M, Okizuka Y, Awano H, Zhang Z, Yamauchi Y, Nishio H, Matsuo M. Mutation spectrum of the dystrophin gene in 442 Duchenne/Becker muscular dystrophy cases from one Japanese referral center. Journal of Human Genetics. 2010;55(6):379-388. doi:10.1038/jhg.2010.49

56. Koenig M, Beggs AH, Moyer M, Scherpf S, Heindrich K, Bettecken T, Meng G, Müller CR, Lindlöf M, Kaariainen H, et al. The molecular basis for duchenne versus becker muscular dystrophy: Correlation of severity with type of deletion. American Journal of Human Genetics. 1989;45(4):498-506. doi:10.1016/1

57. Flanigan KM, Dunn DM, Von Niederhausern A, Soltanzadeh P, Gappmaier E, Howard MT, Sampson JB, Mendell JR, Wall C, King WM, et al. Mutational spectrum of DMD mutations in dystrophinopathy patients: Application of modern diagnostic techniques to a large cohort. Human Mutation. 2009;30(12):16571666. doi:10.1002/humu. 21114

58. Aartsma-Rus A, Van Deutekom JCT, Fokkema IF, Van Ommen GJB, Den Dunnen JT. Entries in the Leiden Duchenne muscular dystrophy mutation database: An overview of mutation types and paradoxical cases that confirm the reading-frame rule. Muscle and Nerve. 2006;34(2):135-144. doi:10.1002/mus.20586

59. Ricotti V, Mandy WPL, Scoto M, Pane M, Deconinck N, Messina S, Mercuri E, Skuse DH, Muntoni F. Neurodevelopmental, emotional, and behavioural problems in Duchenne muscular dystrophy in relation 
to underlying dystrophin gene mutations. Developmental Medicine and Child Neurology. 2016;58(1):77-84. doi:10.1111/dmcn.12922

60. Thangarajh M, Hendriksen J, McDermott MP, Martens W, Hart KA, Griggs RC. Relationships between DMD mutations and neurodevelopment in dystrophinopathy. Neurology. 2019;93(17):E1597-E1604. doi:10.1212/WNL.0000000000008363

61. Birnkrant DJ, Bushby K, Bann CM, Apkon SD, Blackwell A, Brumbaugh D, Case LE, Clemens PR, Hadjiyannakis S, Pandya S, et al. Diagnosis and management of Duchenne muscular dystrophy, part 1: diagnosis, and neuromuscular, rehabilitation, endocrine, and gastrointestinal and nutritional management. The Lancet Neurology. 2018;17(3):251-267. http://dx.doi.org/10.1016/S1474-4422(18)30024-3. doi:10.1016/S14744422(18)30024-3

62. Birnkrant DJ, Bushby K, Bann CM, Alman BA, Apkon SD, Blackwell A, Case LE, Cripe L, Hadjiyannakis S, Olson AK, et al. Diagnosis and management of Duchenne muscular dystrophy, part 2: respiratory, cardiac, bone health, and orthopaedic management. The Lancet Neurology. 2018;17(4):347-361. http://dx.doi.org/10.1016/S1474-4422(18)30025-5. doi:10.1016/S1474-4422(18)30025-5

63. Birnkrant DJ, Bushby K, Bann CM, Apkon SD, Blackwell A, Colvin MK, Cripe L, Herron AR, Kennedy A, Kinnett K, et al. Diagnosis and management of Duchenne muscular dystrophy, part 3: primary care, emergency management, psychosocial care, and transitions of care across the lifespan. The Lancet Neurology. 2018;17(5):445-455. http://dx.doi.org/10.1016/S1474-4422(18)30026-7. doi:10.1016/S1474-4422(18)30026-7

64. Eagle M, Bourke J, Bullock R, Gibson M, Mehta J, Giddings D, Straub V, Bushby K. Managing Duchenne muscular dystrophy - The additive effect of spinal surgery and home nocturnal ventilation in improving survival. Neuromuscular Disorders. 2007;17(6):470-475. doi:10.1016/j.nmd.2007.03.002

65. Drachman DB, Toyka K V., Myer E. Prednisone in Duchenne Muscular Dystrophy. The Lancet. 1974;304(7894):1409-1412. doi:10.1016/S0140-6736(74)90071-3

66. Gloss D, Moxley RT, Ashwal S, Oskoui M. Practice guideline update summary: Corticosteroid treatment of Duchenne muscular dystrophy - Report of the Guideline Development Subcommittee of the American Academy of Neurology. Neurology. 2016;86(5):465-472. doi:10.1212/WNL.0000000000002337

67. Matthews E, Brassington R, Kuntzer T, Jichi F, Manzur AY. Corticosteroids for the treatment of Duchenne muscular dystrophy. Cochrane Database of Systematic Reviews. 2016;2016(5). doi:10.1002/14651858.CD003725.pub4

68. Escolar DM, Hache LP, Clemens PR, Cnaan A, McDonald CM, Viswanathan V, Kornberg AJ, Bertorini TE, Nevo Y, Lotze T, et al. Randomized, blinded trial of weekend vs daily prednisone in Duchenne muscular dystrophy. Neurology. 2011;77(5):444-452. doi:10.1212/WNL.0b013e318227b164

69. Connolly AM, Zaidman CM, Golumbek PT, Cradock MM, Flanigan KM, Kuntz NL, Finkel RS, McDonald CM, Iannaccone ST, Anand P, et al. Twice-weekly glucocorticosteroids in infants and young boys with Duchenne muscular dystrophy. Muscle and Nerve. 2019;59(6):650-657. doi:10.1002/mus.26441

70. Aartsma-Rus A, Fokkema I, Verschuuren J, Ginjaar I, van Deutekom J, van Ommen G-J, den Dunnen JT. Theoretic applicability of antisense-mediated exon skipping for Duchenne muscular dystrophy mutations. Human Mutation. 2009 [accessed 2020 May 23];30(3):293-299. http://doi.wiley.com/10.1002/humu.20918. doi:10.1002/humu.20918

71. Mendell JR, Rodino-Klapac LR, Sahenk Z, Roush K, Bird L, Lowes LP, Alfano L, Gomez AM, Lewis S, Kota J, et al. Eteplirsen for the treatment of Duchenne muscular dystrophy. Annals of Neurology. 2013;74(5):637-647. doi:10.1002/ana.23982

72. Charleston JS, Schnell FJ, Dworzak J, Donoghue C, Lewis S, Chen L, David Young G, Milici AJ, Voss J, Dealwis U, et al. Eteplirsen treatment for Duchenne muscular dystrophy. Neurology. 2018;90(24):e2135e2145. doi:10.1212/WNL.0000000000005680 
73. Cirak S, Arechavala-Gomeza V, Guglieri M, Feng L, Torelli S, Anthony K, Abbs S, Garralda ME, Bourke J, Wells DJ, et al. Exon skipping and dystrophin restoration in patients with Duchenne muscular dystrophy after systemic phosphorodiamidate morpholino oligomer treatment: An open-label, phase 2, doseescalation study. The Lancet. 2011;378(9791):595-605. http://dx.doi.org/10.1016/S0140-6736(11)60756-3. doi:10.1016/S0140-6736(11)60756-3

74. Khan N, Eliopoulos H, Han L, Kinane TB, Lowes LP, Mendell JR, Gordish-Dressman H, Henricson EK, McDonald CM. Eteplirsen treatment attenuates respiratory decline in ambulatory and nonambulatory patients with duchenne muscular dystrophy. Journal of Neuromuscular Diseases. 2019;6(2):213225. doi:10.3233/JND-180351

75. Mendell JR, Goemans N, Lowes LP, Alfano LN, Berry K, Shao J, Kaye EM, Mercuri E. Longitudinal effect of eteplirsen versus historical control on ambulation in Duchenne muscular dystrophy. Annals of Neurology. 2016;79(2):257-271. doi:10.1002/ana.24555

76. Ledford H. US government approves controversial drug for muscular dystrophy. Nature. 2020. doi:10.1038/nature.2016.20645

77. Frank DE, Schnell FJ, Akana C, El-Husayni SH, Desjardins CA, Morgan J, Charleston JS, Sardone V, Domingos J, Dickson G, et al. Increased dystrophin production with golodirsen in patients with Duchenne muscular dystrophy. Neurology. 2020 Mar 5:10.1212/WNL.0000000000009233. doi:10.1212/wnl.0000000000009233

78. Aartsma-Rus A, Corey DR. The 10th Oligonucleotide Therapy Approved: Golodirsen for Duchenne Muscular Dystrophy. Nucleic Acid Therapeutics. 2020;30(2):67-70. doi:10.1089/nat.2020.0845

79. Hirawat S, Welch EM, Elfring GL, Northcutt VJ, Paushkin S, Hwang S, Leonard EM, Almstead NG, Ju W, Peltz SW, et al. Safety, tolerability, and pharmacokinetics of PTC124, a nonaminoglycoside nonsense mutation suppressor, following single- and multiple-dose administration to healthy male and female adult volunteers. Journal of Clinical Pharmacology. 2007;47(4):430-444. doi:10.1177/0091270006297140

80. McDonald CM, Campbell C, Torricelli RE, Finkel RS, Flanigan KM, Goemans N, Heydemann P, Kaminska A, Kirschner J, Muntoni F, et al. Ataluren in patients with nonsense mutation Duchenne muscular dystrophy (ACT DMD): a multicentre, randomised, double-blind, placebo-controlled, phase 3 trial. The Lancet. 2017;390(10101):1489-1498. doi:10.1016/S0140-6736(17)31611-2

81. Mercuri E, Muntoni F, Osorio AN, Tulinius M, Buccella F, Morgenroth LP, Gordish-Dressman H, Jiang J, Trifillis P, Zhu J, et al. Safety and effectiveness of ataluren: comparison of results from the STRIDE Registry and CINRG DMD Natural History Study. Journal of Comparative Effectiveness Research. 2020 [accessed 2020 May 23];9(5):341-360. https://www.futuremedicine.com/doi/10.2217/cer-2019-0171. doi:10.2217/cer2019-0171

82. Bushby K, Finkel R, Wong B, Barohn R, Campbell C, Comi GP, Connolly AM, Day JW, Flanigan KM, Goemans N, et al. Ataluren treatment of patients with nonsense mutation dystrophinopathy. Muscle and Nerve. 2014 [accessed 2020 May 23];50(4):477-487. http://doi.wiley.com/10.1002/mus.24332. doi:10.1002/mus.24332

83. EMA. Translarna: EPAR - Product Information. 2020. https://www.ema.europa.eu/en/documents/productinformation/translarna-epar-product-information_en.pdf

84. FDA. FDA Briefing Document: Peripheral and Central Nervous System Drugs Advisory Committee Meeting (NDA 200896 Ataluren). 2017 [accessed 2020 May 23]. https://www.fda.gov/media/112565/download

85. Hoffman EP, Schwartz BD, Mengle-Gaw LJ, Smith EC, Castro D, Mah JK, Mcdonald CM, Kuntz NL, Finkel RS, Guglieri M, et al. Vamorolone trial in Duchenne muscular dystrophy shows dose-related improvement of muscle function. Neurology. 2019;93(13):E1312-E1323. doi:10.1212/WNL.0000000000008168 
86. Waldrop MA, Flanigan KM. Update in Duchenne and Becker muscular dystrophy. Current Opinion in Neurology. 2019;32(5):722-727. doi:10.1097/WCO.0000000000000739

87. Salmaninejad A, Jafari Abarghan Y, Bozorg Qomi S, Bayat H, Yousefi M, Azhdari S, Talebi S, Mojarrad M. Common therapeutic advances for Duchenne muscular dystrophy (DMD). International Journal of Neuroscience. 2020. doi:10.1080/00207454.2020.1740218

88. Mendell JR, Campbell K, Rodino-Klapac L, Sahenk Z, Shilling C, Lewis S, Bowles D, Gray S, Li C, Galloway G, et al. Dystrophin immunity in Duchenne's muscular dystrophy. New England Journal of Medicine. 2010;363(15):1429-1437. doi:10.1056/NEJMoa1000228

89. Chamberlain JR, Chamberlain JS. Progress toward Gene Therapy for Duchenne Muscular Dystrophy. Molecular Therapy. 2017;25(5):1125-1131. http://dx.doi.org/10.1016/j.ymthe.2017.02.019. doi:10.1016/j.ymthe.2017.02.019

90. Mendell JR, Sahenk Z, Lehman K, Nease C, Lowes LP, Miller NF, Iammarino MA, Alfano LN, Nicholl A, Al-Zaidy S, et al. Assessment of Systemic Delivery of rAAVrh74.MHCK7.microdystrophin in Children With Duchenne Muscular Dystrophy. JAMA Neurology. 2020 Jun 15. https://jamanetwork.com/journals/jamaneurology/fullarticle/2767086. doi:10.1001/jamaneurol.2020.1484

91. Song Y, Morales L, Malik AS, Mead AF, Greer CD, Mitchell MA, Petrov MT, Su LT, Choi ME, Rosenblum ST, et al. Non-immunogenic utrophin gene therapy for the treatment of muscular dystrophy animal models. Nature Medicine. 2019;25(10):1505-1511. http://dx.doi.org/10.1038/s41591-019-0594-0. doi:10.1038/s41591-019-0594-0

92. Chicoine LG, Rodino-Klapac LR, Shao G, Xu R, Bremer WG, Camboni M, Golden B, Montgomery CL, Shontz K, Heller KN, et al. Vascular delivery of rAAVrh74.MCK.GALGT2 to the gastrocnemius muscle of the rhesus macaque stimulates the expression of dystrophin and laminin $\alpha 2$ surrogates. Molecular Therapy. 2014;22(4):713-724. doi:10.1038/mt.2013.246

93. Xu R, Jia Y, Zygmunt DA, Martin PT. rAAVrh74.MCK.GALGT2 Protects against Loss of Hemodynamic Function in the Aging mdx Mouse Heart. Molecular Therapy. 2019;27(3):636-649. doi:10.1016/j.ymthe.2019.01.005

94. Xu R, Camboni M, Martin PT. Postnatal overexpression of the CT GalNAc transferase inhibits muscular dystrophy in $\mathrm{mdx}$ mice without altering muscle growth or neuromuscular development: Evidence for a utrophin-independent mechanism. Neuromuscular Disorders. 2007;17(3):209-220. doi:10.1016/j.nmd.2006.12.004

95. Childers MK, Joubert R, Poulard K, Moal C, Grange RW, Doering JA, Lawlor MW, Rider BE, Jamet T, Danièle N, et al. Gene therapy prolongs survival and restores function in murine and canine models of myotubular myopathy. Science Translational Medicine. 2014;6(220):220ra10. doi:10.1126/scitranslmed.3007523

96. Kaiser J. Boys with a rare muscle disease are breathing on their own, thanks to gene therapy. Science. 2019 May 2. doi:10.1126/science.aax9005

97. Waldrop MA, Kolb SJ. Current Treatment Options in Neurology - SMA Therapeutics. Current Treatment Options in Neurology. 2019;21(6). doi:10.1007/s11940-019-0568-z

98. Amoasii L, Hildyard JCW, Li H, Sanchez-Ortiz E, Mireault A, Caballero D, Harron R, Stathopoulou TR, Massey C, Shelton JM, et al. Gene editing restores dystrophin expression in a canine model of Duchenne muscular dystrophy. Science. 2018;362(6410):86-91. doi:10.1126/science.aau1549

99. Chicoine LG, Montgomery CL, Bremer WG, Shontz KM, Griffin DA, Heller KN, Lewis S, Malik V, Grose WE, Shilling CJ, et al. Plasmapheresis eliminates the negative impact of AAV antibodies on microdystrophin gene expression following vascular delivery. Molecular Therapy. 2014;22(2):338-347. doi:10.1038/mt.2013.244 
100. Orlowski A, Katz MG, Gubara SM, Fargnoli AS, Fish KM, Weber T. Successful Transduction with AAV Vectors after Selective Depletion of Anti-AAV Antibodies by Immunoadsorption. Molecular Therapy Methods and Clinical Development. 2020;16:192-203. doi:10.1016/j.omtm.2020.01.004

101. Stevens D, Claborn MK, Gildon BL, Kessler TL, Walker C. Onasemnogene Abeparvovec-xioi: Gene Therapy for Spinal Muscular Atrophy. Annals of Pharmacotherapy. 2020. doi:10.1177/1060028020914274

102. Malone DC, Dean R, Arjunji R, Jensen I, Cyr P, Miller B, Maru B, Sproule DM, Feltner DE, Dabbous O. Cost-effectiveness analysis of using onasemnogene abeparvocec (AVXS-101) in spinal muscular atrophy type 1 patients. Journal of Market Access \& Health Policy. 2019;7(1):1601484. doi:10.1080/20016689.2019.1601484

Table 1. Approved medications for spinal muscular atrophy and Duchenne muscular dystrophy in the United States.

Legend: * - Approved for use in Europe for children with SMA less than 21 kilograms (approximately under 5 years of age) and up to threeSMN2 copies. \# - Initial approval for deflazacort for use in children with DMD five years of age and older was revised to include children who are two years of age and older on June 7,2019 .

Figure 1. Clinical decision-making algorithm for the use of gene replacement therapy in spinal muscular atrophy.

Legend: ${ }^{\S}$ - Evaluation for SMN2 copy number should be conducted during genetic confirmation to inform prognosis and aid in conversations about medical decision-making even though treatments in the United States are not currently limited by SMN2copy number. ${ }^{+}$- Approved for use in Europe for children with SMA less than 21 kilograms (approximately under 5 years of age) and up to three SMN2 copies. ++ One option includes the splicing modifier risdiplam, given as a daily enteral medication, which is currently available under an expanded access program (NCT04256265).

\section{Hosted file}

Table 1.docx available at https://authorea.com/users/338796/articles/465213-overview-ofgene-therapy-in-spinal-muscular-atrophy-and-duchenne-muscular-dystrophy

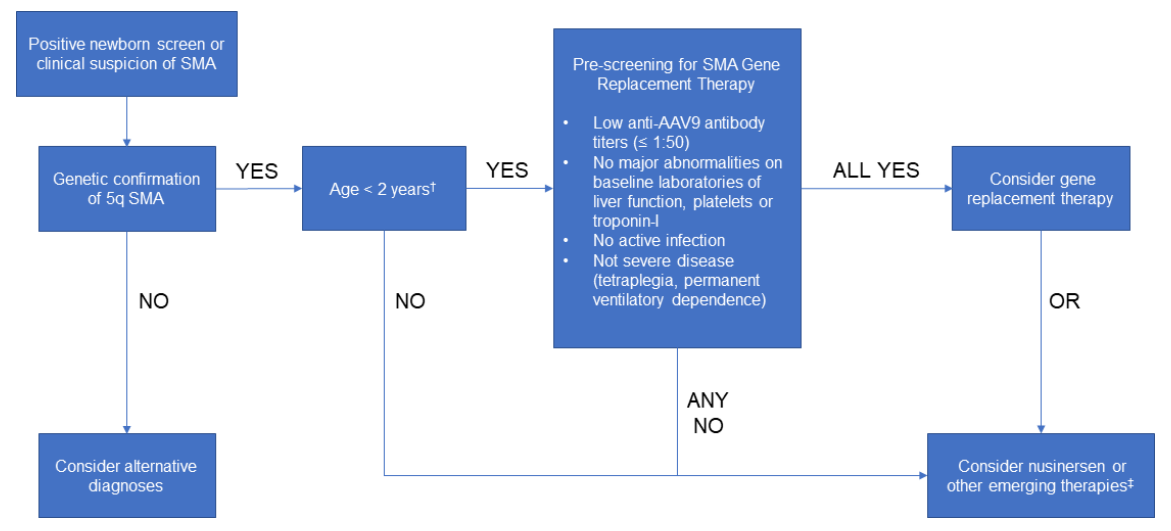

